\title{
Contents Volume 4
}

No. 1

\section{Editorials}

Thirty years after thalidomide: still plenty to do K.H. Kimbel (Germany)

Good enough for Iganga?

G. Dukes (Netherlands)

\section{Regular Papers}

In vitro investigation of the possible influence of inorganic mercury and hydrogen peroxide on the formation of peroxides in a polyunsaturated fatty acid system (linoleic acid)

B. Fredin and L. Krabisch (Sweden)

Registration of drug use in a birth defect monitoring system: a priority worthy of emphasis!

C.S. De Vries, H.E.K. De Walle, M.C. Cornel and L.T.W. De Jongvan den Berg (Netherlands)

Adverse drug reaction reporting in Europe: some problems of comparison

M. Lindquist and I.R. Edwards (Sweden)

Medication use during pregnancy in relation to maternal characteristics P.H. Verkerk, J.D. Reerink, W.P. Herngreen and S.E. Buitendijk

Liability of the pharmacist and drug induced injury: practical implications of the current liability debate for pharmacists

F. Moss (Netherlands)

Human growth hormone: challenge to non-therapeutic and experimental use J. Mendelson (USA)

Reviews

Cyclofem: a new once-a-month injectable contraceptive

Reorganisation of the health care systems of Eastern Europe. Using the experience of a new start in Eastern Germany following German re-unification

B. Schirmer (Germany)

Reports

Obesitas

Symposium: controversies in asthma therapy 


\section{Profile}

DES Daughters vs. several Pharmaceutical Companies

\section{Book Review}

Bad medicine: the prescirption drugindustry in the third world

Forthcoming Meetings

Information for Authors $\quad 101$

No. 2

Regular Papers

Liver transplantation: a success in most cases. But what about the less fortunate patients?

J. Heyink and T. Tymstra (Netherlands)

Mortality associated with surgery: a case review study K. Gannon (UK)

A study on the awareness of the use of medicines among high school students aged 14-16 years in a co-educational school in North India

T. Oommen (India)

Psychiatry's role in the holocaust

P.R. Breggin (USA)

\section{Reviews}

The biological effects of radiation

R.A. De Vries, M. De Bruin, J.J.M. Marx and A. Van de Wiel (Netherlands)

Unnecessary injections in developing countries: the risk and costs H.V. Wyatt and S. Mahadevan (UK, India)

Information for Authors

No. 3

\section{Editorial}

The "FDA approval defense": penetrating the protective shield D.W. Sigelman (USA)

\section{Regular Papers}

Vascular complications following therapeutic and diagnostic cardiac catheterisation by the femoral artery M. Bitsch, O. Liisberg-Larsen and T.V. Schroeder (Denmark)

Mercury release from dental amalgam fillings 
One-year follow-up after the first prescription of strong analgesics outside hospital

H.T. Sørensen, E. Ejlersen, J. Møller-Petersen, H.H. Rasmussen, H. Hamburger and $F$. Olesen (Denmark)

Safety of maternal long-term indomethacin tocolysis

A. Schoenfeld, M. Hod, P. Merlob, S. Friedman and J. Ovadia (Israel)

Internality and externality correlates of potential drivers among high school pupils in Holon (Israel)

U. Brook and A. Weitzman (Israel)

\section{Case Histories}

Recovery from amyotrophic lateral sclerosis and from allergy after removal of dental amalgam fillings

O. Redhe and J. Pleva (Sweden)

\section{Short Report}

The Accutrend ${ }^{\circledR}$ - a safe device for blood glucose determinations in hospitalized patients?

B. Zernikow and E. Michel (Germany)

Profile

The Cochrane Collaboration. Making the results of controlled trials properly accessible

A. Herxheimer (UK)

Hippocrates

Book Review

Risk areas in medical practice

Announcement

Forthcoming Meetings

Contents of Volume 4

Announcement from the Publisher 